\title{
LA FUNCIÓN MILITAR DE LA NOBLEZA EN LOS ORÍGENES DE LA ESPAÑA MODERNA
}

POR

\author{
DAVID GARCÍA HERNÁN
}

\section{RESUMEN - ABSTRACT}

Este artículo pretende mostrar la importancia que tiene la nobleza, como estamento social, dentro de los esquemas del mundo de la guerra a comienzos de la Edad Moderna. En el caso de la España de Felipe II se puede ver con claridad las abundantes implicaciones de los nobles con todo lo que rodea a la violencia auspiciada por Estado - la guerra_, y también incluso la que se aparta de este tipo de cauces «oficiales». Desde un punto de vista propiamente social, se puede observar que la función originaria de la nobleza todavía tiene sentido dentro de la propia ordenación social. El elenco de funciones militares, características, atributos (la simbología de la exaltación de lo guerrero como un enaltecido valor social), y su propia tenencia y disposición de gran número de armas, otorgaban a los nobles un poder, al menos intimidatorio, muy grande. Desde esta perspectiva, su capacidad de maniobra se nos muestra así muy amplia, y configuradora también de determinadas relaciones sociales, entre las que se encuentra la propia capacidad de la nobleza como grupo social para autoperpetuarse en su posición de privilegio..

This article shows the importance of the nobility, as a social order, inside the war's world in the beginning of the Modern Age. In Spain under king Philippe II are very clear the plentiful connections of the nobility with all things around the state's violence - the war-, even the others ways not controlled by himself. From a social point of view, we see that the primitive function of the nobility is important in the social structure. The list of military functions, features, attributes (the symbolism of the war like a good social virtue), and its owner's condition of weapons gives to the noblemen a power, at least intimidator, very great. From this point of view, its manoeuvrability was wide and important in the social relations too. In this way the nobility was able to continue in its privileged position for a long time.

\section{PALABRAS CLAVE - KEY WORDS}

Siglo XVI. España. Felipe II. Guerra. Sociedad. Nobleza. Armas.

Sixteenth Century. Spain. Philippe II. War. Society. Nobility. Weapons.

\section{LA CULTURA DE LA GUERRA EN LA ESPAÑA RENACENTISTA}

En la Europa del Renacimiento la guerra y las actividades militares formaban parte de toda una cultura basada en la violencia y el poder de la fuerza. Una cultura que estaba presente en muchas de las realidades sociales. Así lo reconoce, entre otros, Franco CARDINI, en cuya obra sobre «La cultura de la guerra», concibe el mundo de la guerra en la época preindustrial como toda una cultura, presentada en el pensamiento, las artes, la tecnología, el 
derecho, la economía y otros muchos aspectos ${ }^{1}$. Una mirada atenta sobre el devenir histórico de los grandes imperios nos acerca a la creencia de que existen civilizaciones enteras fundadas sobre la cultura de la guerra, creadas no sólo para responder a las necesidades que engendra, sino también para perpetuarlas. El estudio de todo lo relacionado con la violencia organizada por los estados se nos presenta así como fundamental para comprender no sólo realidades militares, sino también políticas, socio-económicas o culturales ${ }^{2}$.

La época que nos ocupa, los comienzos de la Edad Moderna, es especialmente relevante es este sentido. No cabe duda que la guerra configuraba un propio estilo de vida en la Europa renacentista. A pesar del crecimiento de la diplomacia y del trato cortesano ${ }^{3}$, a pesar de la consideración de desprecio hacia las «viles armas» de fuego, y a pesar de la minusvaloración - parece ser que generalizada - por la profesión del soldado, en los siglos XV y XVI hubo una vigorosa reacción a favor de la guerra. Se dio entonces una deliberada re-inflación de las virtudes y el esplendor militares que desembocó en un culto positivo de la guerra. En Francia, Alemania, Italia y España, las órdenes de caballería, tanto religiosa como secular restituyeron el heroísmo y la gloria de la vida del soldado ${ }^{4}$. La armadura se volvió más elaborada y ornamentada, y los militares mostraron en sus torneos y en sus desfiles ceremoniales más grandiosidad. Artistas, escritores y maestros de espectáculos encontraron en la guerra uno de sus temas más recurridos. Hubo además una proliferación de la imaginería militar en las tumbas, en las fachadas, en la madera y las artes plásticas, las tapicerías y el mobiliario de las casas. Las virtudes militares, valor, lealtad, obediencia, temperamento, capacidad de sufrimiento, etc., fueron celebradas, y los retratos del ideal del soldado no se alejaron de los del hombre ideal. De esta forma, tanto el esplendor como las miserias de la guerra pasaron a ser publicadas en la imprenta, en pinturas, piedras, y comedias, etc. Hasta el punto de que tanta atención y discusiones sobre la guerra, voluntarias o propagandísticas, nos han dejado innumerables testimonios sobre ella.

En este escenario de exaltación de la guerra y la violencia, es un hecho que tanto reyes como príncipes y eclesiásticos tomaron un interés personal en relación a las armas. Los grandes nobles estaban orgullosos de ser maestros de artillería y desde la adaptación de Vegetius de Cristino de Pisa, en los comienzos del siglo XV, y en la literatura sobre la guerra que leían hubo un lugar destacado para las armas de fuego ${ }^{5}$. No obstante, en un principio hubo serios rechazos por parte de la mentalidad nobiliaria, que no veía con buenos ojos que las armas de fuego no hicieran distinciones sociales a la hora de dar en el blanco ${ }^{6}$. Son muchas las alusiones contemporáneas hacia la «vileza» de aquéllas. Quizás la más expresiva sea la de Don Quijote cuando se expresaba en estos significativos términos:

1 CARDINI, F.: Quell 'Antica festa crudele. Guerra e cultura della guerra dall 'età feudale alla Grande Rivoluzione, Florencia, 1982.

2 Un estudio muy general desde estas perspectivas es la conocida obra de KENNEDY, P.: Auge y caída de las grandes potencias, Barcelona, 1989.

3 Vid. Mattingly, G.: La diplomacia del renacimiento, Madrid, 1970 ; además, por supuesto, del recurrido clásico de Castiglione, B.: El Cortesano, Madrid, Espasa-Calpe, 1992.

4 El cada vez más atendido estudio de las órdenes militares en la Edad Moderna en España es la prueba más evidente de su importancia en este nuevo contexto histórico. Valores tradicionales medievales presentes en los siglos modernos con igual o aún mayor fuerza social. Vid., entre otros, Postigo CASTELLANO, E.: Honor y privilegio en la Corona de Castillla. El Consejo de las órdenes y los caballeros de hábito en el siglo XVII, Valladolid, 1988; WRIGHT, L.P.: «The Military Orders in Sixteenth and Seventeenth Century Spanish Society», Past and Present, 43, (1969); y FERNÁNDEZ IZQUIERDO, F.: La Orden Militar de Calatrava en el siglo XVI: Infraestructura institucional: Sociología y prosopografía de sus caballeros, Madrid, C.S.I.C., 1992.

5 Las ilustraciones del «Weisskunig» de Maximiliano I pusieron de manifiesto que el entrenamiento en la fabricación y uso del cañon era, junto con la caza y los torneos, parte del entrenamiento rutinario de los caballeros cristianos. HALE, J.: «War and public opinion in the fifteenth and sixteenth centuries», Past and Present, 22, (1962).

6 PudDU, R.: El soldado gentilhombre, Barcelona, 1984. 


\begin{abstract}
«Bien hayan aquellos benditos siglos que carecieron de la espantable furia de aquestos endemoniados instrumentos de la artillería, a cuyo inventor tengo para mí que en el infierno se le está dando el premio de su diabólica invención, con la cual dio causa que un infame y cobarde brazo quite la vida a un valeroso caballero, y que, sin saber cómo o por dónde, en la mitad del coraje y brío que enciende y anima a los valientes pechos, llega una desmandada bala, disparada de quien quizá huyó y se espantó del resplandor que hizo el fuego al disparar de la maldita máquina, y corta y acaba en un instante los pensamientos y vida de quien la merecía gozar luengos siglos» ${ }^{7}$.
\end{abstract}

A pesar de estos resquemores, en general las armas de fuego fueron aceptadas por una abrumadora mayoría de soldados caballeros. Incluso por la Iglesia, que reconoció a Santa Bárbara como la patrona de los armeros.

Así pues, los valores de la época renacentista no supusieron ni mucho menos un límite a la explotación de las armas de fuego. En el plano de los hechos y desde un punto de vista general, aunque desde el siglo XIV hubo signos de repulsa y escrúpulos morales, si hubiésemos preguntado, como plantea HALE, que si moderó la opinión pública el potencial destructivo de las armas de fuego, la respuesta hubiera sido tajantemene no $^{8}$.

En la Monarquía Hispánica, como en el resto de los territorios europeos, la idea de Estado en la Edad Moderna, en cuanto a su constitución interna y su articulación, está muy directamente relacionada con el mundo de la guerra. Es más, el desarrollo de los ejércitos se ha constituido en uno de los elementos diferenciados para la existencia o no del Estado verdaderamente moderno, sobre todo en el siglo XVI. Lo militar está presente no sólo en la articulación, sino en la propia justificación del Estado, cuyo pensamiento político afecto está plagado de demostraciones del éxito militar en el pasado a través de las narraciones de los historiadores. La propaganda basada en los hechos guerreros va a jugar también un papel esencial para dirigir la opinión pública a favor del poder monárquico. No hay nada más que echar un ojo sobre casi la totalidad de las obras justificadoras y exaltadoras del poder monárquico para comprobar, con monótona insistencia, las constantes alusiones a los hechos de armas y a las cualidades militares de los soberanos para darse cuenta de esta evidencia.

Asimismo, hoy ya nadie duda que existen unas intensas e imbricadas relaciones entre la guerra y la organización social. Corvisier ha expuesto con claridad didáctica un esquema clásico de las relaciones entre la guerra y la sociedad basado en tres puntos fundamentales que se pueden aplicar perfectamente para el caso de la Monarquía Hispánica: -la sociedad como inspiradora de formas de guerra, -la guerra como agente de transformación social, y -la guerra como principio de la organización social ${ }^{9}$. Pero además, no podemos dejar de tener presente un hecho fundamental que cada vez está teniendo más importancia como referencia interpretativa. Si bien es cierto que los condicionantes económicos, sociales, políticos o culturales son importantes para que se dé un cambio social (en la dirección que sea), no deja tampoco de ser verdad que quienes controlan el poder militar, la fuerza de las armas, son absolutamente decisivos para que se produzcan o no determinadas transformaciones que afectan al conjunto de los ciudadanos. Los poseedores físicos de las armas, ofensivas y/o defensivas, o quienes tienen su control desde el punto de vista técnico o material, en última instancia pueden encauzar el ritmo de la Historia, muchas veces sin proponérselo en un principio, tanto para los cambios como para las permanencias. Así, por ejemplo, el ejército como agente de cambio social (en el más amplio sentido del término) y, en definitiva, como una de las causas importantes de la revolución, ha sido también recientemente analizado, con argumentos muy agudos por ALDER, en cuya obra bastante técnica sobre los ingenieros militares de artillería analiza la función de estos importantes miembros del cuerpo social del ejérci-

7 Cervantes SaAvedra, M.: El ingenioso hidalgo Don Quijote de la Mancha, Ed. De J. Pérez del Hoyo, Madrid, 1963. $1^{\text {a }}$ Parte, Cap. XXXVIII, pág. 206.

8 HALE, J.: «War and public opinion in the fifteenth and sixteenth centuries», Past and Present, 22, (1962).

9 CORVISIER, A.: La guerre. Essais historiques, Paris, 1995. 
to en el cambio hacia una sociedad que les fuera más afín a sus intereses particulares y que reconociera el verdadero valor de la recién adquirida meritocracia ${ }^{10}$.

Es, en nuestra opinión, desde este último prisma de interpretación como podemos sacar a la luz determinadas realidades históricas sobre las relaciones de poder en la Monarquía Hispánica que de otra forma permanecen algo confusas. No cabe duda que para explicar la actividad militar - esencial, como es sabido, desde el punto de vista presupuestario- de este poderoso estado en la época del Renacimiento hay que recurrir, prácticamente en todos de sus múltiples aspectos, al papel que juega un grupo social tradicionalmente ligado a la actividad guerrera como es la nobleza. Siendo los cambios en la Europa del Antiguo Régimen bastante más escasos y de menor intensidad que las permanencias, el esquema de la función guerrera de la nobleza permenecerá presente a lo largo no sólo del Renacimiento, sino incluso hasta el siglo XVIII y adopta unas posiciones, desde nuestro punto de vista, mucho más medievales que modernas, con todas las implicaciones que esto va a traer consigo en la propia política del Estado. No es difícil encontrar muestras de esta consideraciónen en toda Europa. De hecho, en Gran Bretaña, por ejemplo, el interés por el ejército de los monarcas (que quisieron ser también jefes del ejército) y la inclinación hacia él de la nobleza hicieron que el cuerpo de oficiales transmitiera los ideales aristocrácticos a las sociedades coloniales ${ }^{11}$. En época tan avanzada como finales del siglo XVIII, un hombre tan poco sospechoso de inmovilismo como Washington creía firmemente que sólo los caballeros debían ocupar los cargos del ejército. La relación entre nobleza y monarquía con respecto al ejército seguía siendo, por el momento, beneficiosa para ambas. En los países como España el rey tenía ventaja para reclutar soldados porque los hidalgos aceptaban servir en todos los niveles del ejército real ${ }^{12}$.

A lo largo de la Edad Media, la respuesta que dan los componentes del orden nobiliario a su conceptualización como bellatores, había sido en España particularmente consecuente. El proceso de la Reconquista «invitaba» como ninguno al protagonismo del estamento guerrero por antonomasia, llevando consigo el fenómeno el establecimiento de diferencias sociales: «Sy el saber de las armas çeçase, no avría diferençia del cauallero al labrador» escribía el intelectual y político Alonso de Cartagena ${ }^{13}$. Si bien la nobleza no era lo mismo que la actividad guerrera, en una sociedad dotada esencialmente de una ética militar el comportamiento noble y sus más enaltecidos valores (lealtad, valor, fama, etc.) se asociaban casi miméticamente en aquel contexto histórico. Los largos siglos de existencia de la frontera contra el Islam no sólo condicionaron estas actividades guerreras que determinaron toda una serie de categorías nobiliarias $^{14}$, sino que, en esta perspectiva de permanencia de esquemas mentales — que, como hemos apuntado más arriba, se da en la Edad Moderna - pesaron como una losa en los años del Renacimiento en España. No sólo en el reinado caballeresco - como el propio monarca- de Carlos V, sino en el a priori más burocrático y centralizador de Felipe II ${ }^{15}$.

10 ALDER, K.: Engineering the Revolution, Arms and Enlightenment in France, 1763-1815., Princenton, New Jersey, 1997.

11 Bowen, H.V.: War and British society, 1688-1815, Cambridge, 1998, pág.49.

12 Pese a que en países como Polonia, al contrario, no se dan esas circustancias, ya que la nuemerosa «szlachta» sirve fundamentalmente en provecho de los boyardos CORVISIER, A.: La guerre ... Op. Cit., págs. 260-261.

13 Cit. por Gibello Bravo, V.M.: La imagen de la nobleza castellana en la Baja Edad Media, Cáceres, 1999, pág. 55

14 Expuestas con cierta sistematización por LOURIE, E.: «A Society organized for War: Medieval Spain», Past and Present, 35, (1996).

15 Una buena y reciente síntesis sobre las claves más importantes de este reinado la tenemos en MARTíNEZ RUIZ, E.: «Felipe II en la encrucijada: 1566-1575», Madrid. Revista de arte, geografía e Historia, º1, (1998). 


\section{LA PERSISTENCIA DE LOS VALORES GUERRERO-NOBILIARIOS BAJO FELIPE II}

Es cierto que - relativamente- hubo en el siglo XVI en España un declive de interés de la nobleza en las actividades militares, según remarca Elliott, en comparación con otros paí$\operatorname{ses}^{16}$. Pero tambien es incuestionable que los principios de organización de la actividad guerrera seguían girando alrededor de los nobles y del ideal aristocrático. En la Edad Media es lugar común la manifestación de que el valor y lo violento eran ejes de la vida de los nobles. Pero en la llamada Edad Moderna, como en su día manifestó Maravall, el valor físico continuaba mostrándose como un ideal de comportamiento sólo reservado a los merecedores de los más altos honores de carácter social, dentro de una estrategia de perpetuación del paradigma caballeresco y la más alta consideración del valor militar ${ }^{17}$. Lo cierto es que para hacer la guerra había todavía un buen puñado de motivos que se podían considerar como esencialmente nobiliarios en la época que nos ocupa. Según nos relata Diego Hurtado de Mendoza en sus Comentarios de la guerra de Granada se alistaron para combatir la sublevación de los moriscos en 1568, entre otros, por amistad hacia el Marqués de Mondéjar, por la memoria de sus antepasados y «por el ruido y vanidad de la guerra» ${ }^{18}$. Pero nada más revelador de la pervivencia de los esquemas nobiliarios medievales en la actividad guerrera como la forma de recompensar que tenía el rey prudente a sus capitanes y que podemos hoy analizar en un manuscrito bien explícito de la Biblioteca Nacional en Madrid. En fecha tan avanzada como 1596, para recompensar los méritos del capitán Gaspar Ruiz de Cortazar y darle nuevas armas el rey prudente alegaba los siguientes motivos:

\footnotetext{
«Y porque de vuestros seruicios, y persona, quede perpetua memoria a vuestros descendientes y sucessores de la Casa de Cortazar, fuéssemos seruido de concederos que al escudo de las Armas de la vuestra casa, q. son un lebrel y un toco, en campo verde, y una banda negra con sus perfiles dorados, podáis añadir y acrecentar un Castillo, y en él un braço arrmado, con la espada desnuda en la mano, y en memoria de las banderas que ganastéis en las dichas tierras, y Castillas, podáis assimismo poner quatro banderas..."19.
}

El texto no puede ser más significativo: los atributos militares (castillo, brazo armado, espada, banderas), junto a la concesión de un emblema nobiliario que se transmitirá de generación en generación por el conducto «natural» de la hidalguía: la sangre.

De la misma forma, para acceder a recompensas de la monarquía en forma de cargos y retribuciones, se recurre igualmente al esquema nobiliario de perpetuación de valores a través de la sangre. Por infinitos se cuentan los memoriales elevados al monarca alegando los méritos que hacían a los solicitantes los más capacitados para hacerse acreeedores de una determinada merced. Los méritos militares son los más enaltecidos, los que se colocan en los lugares más visibles, junto a la consideración, típicamente nobiliaria de los hechos de los antepasados, que valen todavía más que los realizados por uno mismo. Para ocupar puestos de gobierno en Méjico, y para que se le hiciera merced del título perpetuo de Marqués para su casa y mayorazgo, Don Francisco Pacheco de Córdoba y Bocanegra incluía en los informes elevados al monarca en 1603 los hechos de armas de sus abuelos y hasta de sus bisabuelos con todo lujo de detalles ${ }^{20}$.

16 Recogido en HALE, J.: «War and public opinion in the fifteenth and sixteenth centuries», Past and Present, 22, (1962).

17 Maravall, J.A.: Poder, honor y elites en el siglo XVII, Madrid, 1979.

18 Hurtado de MendozA, D.: Comentarios de la guerra de Granada, Memorial Histórico Español, T.XLIX, Madrid, 1948, pág. 35

19 B.N.M. Mss. 11.773, fol. 644 r.

20 B.N.M. Mss. 11.773 , fols. 530 y ss., entre los numerosos ejemplos al respecto. 
Además hay otras muchas acciones de gobierno en las que los soberanos atendieron a estos patrones sociales nobiliarios cuando se trataba de poner en funcionamiento la máquina militar de la Monarquía. Con una simple contemplación de las nóminas de altos cargos militares durante el reinado de Felipe II, se puede ver perfectamente la preferencia y precedencia de los nobles para ocupar los puestos de reponsabilidad ${ }^{21}$, por mucho que el rey quisiera controlarlos a través de sus ayudantes afectos y leales al servicio real ${ }^{22}$. Hubo una gran mayoría de nobles, por ejemplo, en el mando de las compañías de guardias de Castilla en el ejército para la invasión de Portugal ${ }^{23}$. Además, los diferentes tipos de guardias reales, que servían de una forma directa y cotidiana al soberano estaban mandados también por nobles. Don Gomez de Figueroa, Duque de Feria, era el capitán de la guardia española ${ }^{24}$. Más tarde lo sería Don Pedro de Velasco, del Consejo de Guerra ${ }^{25}$. De la Guardia alemana o tudesca el capitán era el Conde Jerónimo de Lodrón ${ }^{26}$, de la guardia de archeros de corps, el capitán era nada menos que el Conde de Horns, caballero del Toisón de Oro ${ }^{27}$.

Pero no sólo en estos niveles de mando. En puestos clave de gobierno de la monarquía, con funciones militares básicas, se encuentran también nobles de alta alcurnia, tomando las más trascendentes de las decisiones. El Marqués de los Vélez, el de Mondéjar, el Duque de Arcos en la guerra contra los moriscos. El Marqués de Santa Cruz en el Mediterráneo, en Portugal y en la isla Tercera. El Duque de Medina Sidonia en la armada contra Inglaterra y en la defensa de la costa de Andalucía ${ }^{28}$. Y qué decir del Príncipe de Eboli (noble creado al calor de la propia decisión de Felipe II, pero al fin y al cabo noble) o del más famoso militar de su época, Don Fernado Alvarez de Toledo, el «gran» Duque de Alba. Estos dos últimos personajes ocuparon, como es sabido los lugares más altos de la política de su tiempo, y en el caso del «Duque de Hierro» se dieron además una serie de condicionantes de carácter militar que confirma con claridad esta idea de la estrecha relación entre milicia y nobleza en el reinado de Felipe II de la que venimos hablando.

Dejando a un lado sus decisiones de política exterior dentro de las rivalidades cortesanas ${ }^{29}$, e incluso sus múltiples campañas que imprimieron un sello característico a los ejércitos de la Monarquía Católica ${ }^{30}$, en un aspecto que se ha insitido poco pero que es fundamen-

21 Su presencia y grado de influencia, dependiendo de las casos, ha sido recientemente constatada por FERNANDEZ CONTI, S.: Los Consejos de Estado y Guerra de la Monarquía Hispana en tiempos de Felipe II (1548-1598), Madrid, 1998.

22 THOMPSON ya señalaba que aunque se llevara una labor de control por parte de los secretarios adscritos a los generales, era un hecho la presencia de los nobles en el mando y los problemas de precedencia y conflictos de autoridad se encontraron con ello a flor de piel. THOMPSON, I.A.A.: Guerra y decadencia: gobierno y administración en la España de los Austrias, 1560-1620, Barcelona, 1981.

23 Al mando de las compañías de caballos ligeros estuvieron Don Alonso de Zúñiga, Don Diego de Sandoval y Don Luis de Guzman; al mando de las compañías de hombres de armas iban: el Marqués de Montemayor, Don Pedro de Sotomayor, Don Luis de Toledo, el Marqués de Aguilar, el Prior Don Fernando, el adelantado de Castilla, el Marqués de Denia, Don Enrique Enríquez, el Conde de Alba de Liste, Don García de Mendoza y el Conde de Oñate. GRACIA RIVAS, M: La «invasión» de Aragón en 1591: una solución militar a las alteraciones del reino, Zaragoza, 1992.

24 A.G.P. S. Histórica, Caja 180. En 1567 el Duque de Feria fue el responsable nada menos que de la prisión del Príncipe Don Carlos, y a quien se encomendó la guardia de su persona, además de al Príncipe de Eboli y a Don Luis de Quijada, todos ellos del Consejo de Estado de Su Majestad.

25 A.G.P. Registros. 5733.

26 A.G.P. S. Histórica. Caja 174.

27 A.G.P. S. Histórica. Caja 165.

28 En los planteamientos generales sobre la política naval de Felipe II se subraya la importancia de estos personajes. Vid. Pi CORRALES, M. de P.: Felipe II y el dominio del mar, Madrid, 1989.

29 Vid. MARTíneZ Millán, J. (Dir.): La Corte de Felipe II, Madrid, 1997.

30 Sin duda Alba es de los personajes más estudiados del reinado de Felipe II. El famoso Epistolario (ALBA, Fernando Alvarez de Toledo, DuQUE DE: Epistolario del III Duque de Alba, Madrid, 1952) nos aporta gran cantidad de información sobre su personalidad. Un retrato bastante convincente es la moderna biografía de MALTBY, W.S.: El Gran Duque de Alba, Madrid, 1985. Con respecto a su modo de combatir ha aparecido hace poco el estudio de ALONSO BAQUER, M.: «Don Fernando Alvarez de Toledo, Tercer Duque de Alba. Semblanza militar», en GARCIA PINACHO, M. del 
tal, Alba se nos revela como un gran teórico militar convencido de la importancia de la sangre y la nobleza para el ejercicio de las armas. En un manuscrito inédito que lleva por título «DISCURSOS ORIGINALES SOBRE EL ESTADO Y MILICIA DE ESPAÑA», localizado en la Bilblioteca Nacional en Madrid ${ }^{31}$, habla de la «Reformación de la Milicia», y es una especie de tratado escrito en forma de discurso donde se ponen de manifiesto muchas cosas importantes sobre el ejército de la época y sobre la propia posición y actitud de este gran aristócrata castellano. El género, no es ni mucho menos nuevo. La tratadística militar había tenido una sólida aceptación en la Castilla de la Edad Media, como síntoma de la preocupación, también desde el punto de vista cultural e intelectual por los temas militares, y los grandes tratados de los clásicos circulaban con cierta intensidad ${ }^{32}$.

Alba no fue ajeno a esta importancia del pensamiento militar, aunque más centrado en aspectos organizativos que de pura estrategia. De su pluma sale un discurso bastante sistemático y técnico (en el sentido de que el autor conoce perfectamente y en profundidad las cuestiones sobre las que está hablando, por su propia experiencia militar) en el que se tratan los principales problemas que aquejan al ejército español de la época y el modo de resolverlos, descendiendo incluso en algunas cuestiones a las explicaciones más particulares sobre aspectos concretos. La posición de Alba es bastante interesante, y denota un grado de implicación no sólo por el ejército, sino por el servicio del rey muy notable, característico, como han constatado varios autores de su forma de comprender su posición en el engranaje del estado como el militar más experimentado al tiempo que miembro de una de las más encumbradas familias nobles.

Alba va repasando uno a uno los principales problemas de la milicia y detallando cuáles son las misiones de los puestos de responsabilidad del ejército, a los que da instrucciones muy precisas con el objeto de corregir los abusos y de contribuir a la mejor organización de las fuerzas y aprovechamiento de los recursos a ellas destinados. Aunque no sólo se limita a examinar las cuestiones dentro del ejército, sino que, con una visión global de la Monarquía, se permite opinar sobre la mejor forma de extraer esos recursos, sobre las directrices básicas de la política exterior (disminuir la potencia de ingleses y rebeldes flamencos), e incluso la forma de equilibrar los gastos e ingresos del Estado con una política de ahorro más racional.

En sus recomendaciones puramente militares, sabedor de los principales defectos que aquejan a la máquina de los tercios, ofrece bastantes disposiciones para combatir la generalizada corrupción, dando cometidos a los diferentes empleos militares para que controlen todo tipo de abusos y fraudes que se producián en el ejército. De todas sus recomendaciones puntuales podemos consignar dos especialmente significativas. En primer lugar la que intenta corregir esos abusos por la jerarquía del mando: «Que los capitanes y alférez ni sargentos se siruan para cosas suyas de los soldados, pues es muy contrario a la buena disciplina militar y a la reputación de la infantería espanyola...» ${ }^{33}$. Después, es realmente interesante también comprobar ese grado de identificación con la empresa común de la Monarquía: «Que los capitanes tengan particular cuydado de platicar a sus soldados lo que deuen hazer inclinándoles y persuadiéndoles hal amor y zelo del seruiçio de Dios y de su rey y a proceder honrrada

\footnotetext{
P. (Ed.): Los Alvarez de Toledo. Nobleza viva, Segovia, 1998, donde este reconocido especialista de Historia Militar lo considera como la figura central de lo que llama la escuela hispanoitaliana de estrategia.

31 B.N.M. Mss. 12.179, Fols. 43-55.

32 Ultimamente se han expuesto las principales obras que circulaban en el siglo XV, su incidencia, y de lo que trataban. RODRÍGUEZ DE VELASCO, J.D.: El debate sobre la caballería en el siglo XV. La tratadística caballeresca castellana en su marco europeo, Salamanca, 1996. Sobre las necesarias reformas del ejército en la España del segundo de los Felipes, la obra más reconocida es la de MARCOS DE ISABA: Cuerpo enfermo de la milicia española, Edición a cargo de E. Martínez Ruiz, Madrid, 1989.

33 Este tipo de abusos, de actualidad por algunas noticias en los últimos años, es de los más denunciados en la Historia general del ejército; y así lo percibe ya Alba. B.N.M. Mss. 12.179, Fol. 48 v.
} 
y christianamente...» ${ }^{34}$. En buena parte de sus recomendaciones también está presente el problema de la falta de pagas y de los motines. Contra éstos se muestra inflexible, a la vez que aboga por una mejor administración de los recursos para que no se den este tipo de excesos.

Además, el Duque de Alba, aunque inmerso lógicamente en los patrones mentales de corte aristocrático para la estratificación social que también influían en la vida militar, aboga por recompensar los méritos en el ejército y el talento (aunque no sea éste todavía capaz de elevar a los soldados a los puestos de mando). En este sentido, es significativa la insistencia en que se han de recompensar los servicios de los soldados que estaban en armas y no de los que se hallaban en la Corte. Esta cuestión se repite varias veces, como reflejo tanto del «mal» caracterísitico y generalizado de la época de medrar en la corte para recibir mercedes vía favoritismo más que otra cosa, como de la voluntad del «Duque de Hierro» de que los méritos se han de otorgar a quien es verdaderamente acreedor de ellos.

Pero lo que a nosotros más nos interesa de este discurso militar es la expresa mención que hace de la nobleza y su función dentro del ejército, cosa que por supuesto no pasa desapercibida - ni mucho menos- para el soldado-escritor Don Fernando Alvarez de Toledo. Con esa visión global y comprometida de la Monarquía de la que venimos hablando, pretende - rayando incluso la traición, en sentido metafórico, a su propia clase- que para aligerar el peso tan enorme del gasto que tiene que soportar el rey por las empresas militares, se descargue parte de ese gasto en los grandes potentados, que debían asumirlo, para que así se beneficiara la Real Hacienda: »...esté a buen recaudo el estado de Su Md. con la menor costa q. sea posible de la real hazienda» ${ }^{35}$. Por lo tanto, aquí ya hay una importante función de la nobleza, de la gran nobleza, otorgada por Alba como reflejo de su relevancia dentro del Estado.

Además, la mentalidad aristocrática en el funcionamiento interno del ejército está presente también, como no podía ser menos, en las recomendaciones del prócer castellano. Habiendo indicado, por ejemplo, que, para evitar abusos y mejor gobernar el ejército, el capitán general no podía nombrar como capitán de una compañía de infantería a quien no tuviera al menos diez años de servicio, esto no lo aplica con rigor a determinados nobles por su condición social. Hace expresa excepción para los «caualleros muy principales» y que hicieren hechos «q. correspondan a su qualidad» ${ }^{36}$, dejando al arbitrio del rey la designación de esos capitanes que no tienen aquella experiencia de diez años pero sí el «valor» de su sangre.

Pero quizás las líneas más reveladoras de la imagen que en la mente de Alba tiene la función militar de la nobleza (aunque en no pocos casos va a estar lejos de corresponderse con la realidad) es cuando afirma que la nobleza que sirve al soberano en el ejército no lo hace por sueldos ni por ayudas de costa «sino para seruir a Dios y ha su md. y para aumentar la Santa Fe Chatólica con las armas ques su professión y por los tales seruicios ser honrrados y acrecentados por su Md. en los officios de guerra y paz y para ser recebidos en el seruiçio de su casa y persona y en las órdenes militares y auentajados en ellas, por todo lo qual y por otras muchas razones conuenientes al seruicio de Dios y de su Md. y bien de sus uasallos se ordene» ${ }^{37}$. Es decir, un planteamiento de la nobleza en cuanto al uso de las armas plegado a los intereses del Estado, encarnados en su nivel supremo de Dios y el rey, con el esquema clásico victorioso desde los Reyes Católicos de lealtad al monarca a cambio de «officios de guerra y paz» y otras mercedes. Tal era la cara más afecta a la Monarquía (por lo menos la más representativa por lo que un personaje de esta categoría significaba) de la altiva y pode-

34 B.N.M. Mss. 12.179, Fol. 48 r.

35 B.N.M. Mss. 12.179, Fol. 43 v. Este tipo se planteamientos también se asumían para los prelados y las ciudades. Vid. MARTínez RuIZ, E.: «Felipe II, los prelados y la defensa de la Monarquía», Congreso internacional Felipe II (1598-1998) Europa dividida, Madrid, 1999; y «Felipe II y la defensa de la Monarquía: las ciudades», Congreso Internacional Madrid, Felipe II y las ciudades de la Monarquía, Madrid, 2000.

36 B.N.M. Mss. 12.179, Fol. 44 v.

37 B.N.M. Mss. 12.179, Fol. 49 v. y 50 r. 
rosa aristocracia castellana. El rey tenía en Alba uno de los instrumentos más válidos para asentar su poder también en el terreno de la intimidación de las armas y los recursos bélicos ${ }^{38}$.

De menor talla pero no menos significativo es el caso del III Conde de Chinchón, otro de los grandes aristócratas que sirvieron al rey prudente en auténticos problemas de estado. Los últimos estudios nos muestran un hombre entregado a la causa del poder real, aunque sin descuidar los intereses de su casa ${ }^{39}$. Fue el prototipo de hombre que puso sus miras en el ascenso a través de las confrontaciones cortesanas, llegando a alcanzar puestos de enorme relevancia, tanto de hecho (miembro de la «Junta de Noche»), como de derecho (Tesorero General de Aragón, director de la política aragonesa, alcaide y guarda mayor de los Alcázares reales y ciudad de Segovia, etc. ${ }^{40}$. Chinchón tuvo una directa intervención en todos los aspectos concernientes al ejército, en detrimento de Idiáquez (político, pero no título), que estaba encargado de los asuntos militares, no sólo por su posición de autoridad respecto a los asuntos aragoneses, sino porque el maestre de campo general Francisco de Bobadilla era pariente y protegido suyo. Cuando se planteó el problema del enfrentamiento con el máximo responsable del ejército de Aragón, Alonso de Vargas, se mostraría a las claras esta especie de alianza. En sus planteamientos militares, entre otras cosas Chinchón había sugerido al rey el traslado de unas compañías de guardas de Castilla a la frontera con Aragón, como medida de fuerza, cosa que llevó a cabo el monarca a partir de 1588. Por otro lado, además de en los asuntos aragoneses, el III Conde de Chinchón también participó activamente en asuntos de dirección militar en la propia corte, como cuestiones relativas a la guardia alemana y los arque$\operatorname{ros}^{41}$. De cualquier forma, personajes como este Conde de Chinchón son los más renombrados, que han ido apareciendo en las páginas de una Historiografía centrada, desde la propia época, en subrayar la tendencia hacia el fortalemiento de un poder real, personificado en la imagen autoritaria de Felipe II, que no podía verse ensombrecido por ningún otro poder del Estado. Pero en realidad son otros muchos los miembros de los niveles del estamento nobiliario que se vieron introducidos de lleno en la actividad militar atendiendo a su «primitiva función».

Presencia, por tanto, generalizada e importante de los nobles en los puestos más importantes de la administración y el gobierno militar. No podía ser de otro modo. Por mucho que lo hubiera pretendido - que no fue el caso-, Felipe II no podía prescindir de los nobles. Ante unos esquemas mentales bastante bien definidos y acordes por completo con la organización social vigente en una época ajena a los cambios substanciales en el orden social - esquemas de los que él mismo y sus colaboradores eran partícipes - no podían dejar de contar con el ordo de los «bellatores», a pesar del acendrado autoritarismo y la división entre los nobles que procuró, de la que nos habla la Historiografía desde el propio Cabrera de Córdoba ${ }^{42}$. No podía prescindir, y, como hemos visto, no lo hizo.

38 Junto a este manuscrito analizado se encuentra otro denominado «Discurso sobre el cargo de Maestre de Campo General de los ejércitos» (B.N.M. Mss. 12.179, Fols. 59-60 r. y v.). Lo escribe el Duque de Alba siendo virrey de Nápoles, gobernador de Milán, mayordomo mayor y del Consejo de Su Majestad, su lugarteniente y capitán general en Italia. En este discurso expone toda serie de pormenores sobre las funciones que debe tener el Maestre de Campo general en el ejército, con instrucciones expresas y muy precisas sobre sus competencias de mando.

39 Está por hacer, como ocurre con otras grandes casas, la historia del régimen señorial del Condado de Chinchón. Un estudio en profundidad aportaría muchas claves para explicar los resortes del poder en terriotorios tan cercanos a la corte como eran los de los Fernández de Bobaddilla.

40 FERNÁNDEZ CONTI lo ha caracterizado hace poco como hombre muy afecto al poder real, que defendía con uñas y dientes (como se pudo demostrar en los sucesos de Aragón, por lo que fue odiado en este reino). Un hombre un tanto militante y casi servil a los designios reales y opositor de todo lo que pudiera obstruir la voluntad real y su autoridad, que procuraba acrecentar por encima de todo. FERNANDEZ CONTI, S.: «La nobleza cortesana: Don Diego de Cabrera y Bobadilla, Tercer Conde de Chinchón», en MARTínEZ MiLlán, J.: La corte de Felipe II, Madrid, 1994.

41 El propio Felipe II llegó a decir que «el conde sabe de estas cosas». FERNÁNDEZ CONTI, S.: «La nobleza cortesana: Don Diego de Cabrera y Bobadilla, Tercer Conde de Chinchón», en MARTínEZ MiLlán, J.: La corte de Felipe II, Madrid, 1994.

42 CABrera de CordobA, L.: Historia de Felipe II, Madrid, Ed. de 1619. 


\section{EL PAPEL MILITAR DEL SEÑORÍO}

Pero todavía más clara es esta necesidad en la consideración del régimen señorial. Sobre esto ya llamó la atención Thompson cuando afirmaba que era una norma insostenible que no se diera poder militar a los grandes ${ }^{43}$, sobre todo porque la importancia militar de los nobles nacía de su situación como grandes terratenientes y de su posición social fortalecida con la endogamia en las relaciones familiares. Como señores de vasallos tenían una intervención directa en la defensa nacional en su dimensión de autoridades intermedias en la articulación de los resortes institucionales del Estado; además de tener un gran prestigio en sus zonas de influencia que muchas veces incluso tenían un carácter marcadamente estratégico, como se pudo ver en las funciones de mando de los siete señores de las tierras adyacentes a Portugal en la campaña de la Anexión de 1580, por ejemplo. Ellos mismos muchas veces recurrieron a su posición para ponerse al servicio del monarca en espera de enjundiosas recompensas, como había pasado en los siglos bajomedievales y como - esperaban- podía pasar en cualquier momento. ¿Cómo si no se explica ese fervor de los grandes castellanos, en participar precisamente en la empresa de la anexión de Portugal, si no es con la esperanza de hacerse acreedores de importantes mercedes?

De esta forma, el papel de la nobleza en la guerra y la administración militar empieza a ser importante, según Thompson, a partir de 1580, y se manifiesta ostensiblemente durante el siglo XVII, que es la época en la que en realidad se centra para esta cuestión su estudio. Así, «en el siglo XVI el señorío casi había perdido sus funciones militares», siendo la participación de la nobleza en el ejército verdaderamente escasa y poco valiosa ${ }^{44}$. Es decir, si nos fijamos, es en los momentos en los que España tuvo la facultad de poder, en palabras de Bennassar, «exportar la guerra» ${ }^{45}$ y cuando, en líneas generales, no hay que defender el propio suelo ${ }^{46}$, cuando la participación de la nobleza se hace más pobre, mientras que en el XVII, con grandes problemas en la Península como los gravísimos de 1640 donde, según Thompson, se recupera el poder militar de la nobleza, viéndose incluso obligada la corona a preservar y reconstruir las fortunas de su nobleza.

No obstante, pensamos que en realidad ese poder nunca desapareció, si bien durante el reinado del rey prudente se mantuvo más bien latente y con una importancia potencial más que realmente factual. Lo que no quiere decir que el monarca dejara de tener en cuenta el «valor del señorío» y de la nobleza en general para todas estas cuestiones. Las circunstancias políticas del momento hicieron oscurecer unos motivos y actitudes nobiliarias con respecto a la milicia que estaban sin embargo e inevitablemente ahí, aunque de forma no tan efusiva como en tiempos anteriores y posteriores. España pasó en estos comienzos de la Edad Moderna de un polo al contrario; es decir del predominio de la actividad guerrera en la Reconquista a la quasi carencia de la idea de defensa del propio territorio hasta bien entrado el siglo XVII. Si lo primero había configurado una participación de la nobleza protagonista a primera vista, lo segundo subrayaría una no participación, pero también a primera vista. En el fondo, el papel militar de la nobleza estaba potencialmente presente, y sólo se tuvieron que mostrar los escenarios bélicos con proximidad para que se manifestaran con toda su expresividad.

43 Refiriéndose al siglo XVII y al nombramiento del Duque de Medina Sidonia para el mando militar en la frontera portuguesa en 1640 afirma que, a pesar de que Dominguez Ortiz no encontrara explicación al respecto, «visto el desarrollo de la organización militar a lo largo de los anteriores 60 años, era la única elección posible», como gran magnate de Andalucía. THOMPSON, I.A.A.: Guerra y decadencia: gobierno y administración en la España de los Austrias, 15601620, Barcelona, 1981

44 ThOMPSON, I.A.A.: Guerra y decadencia: gobierno y administración en la España de los Austrias, 1560-1620, Barcelona, 1981, págs. 181-184.

45 Bennassar, B.: La España del Siglo de Oro, Barcelona, 1983.

46 A partir de la guerra de las Comunidades, con las grandes excepciones de la sublevación de los moriscos, la anexión de Portugal y las alteraciones de Aragón. 
Hay muchas circunstancias claras de esta realidad. De hecho, casi todos los planteamientos expuestos por Thompson en cuanto la importancia del magnate local en el siglo XVII para las tareas militares pensamos que son aplicables en la centuria anterior. El ser miembro acomodado de la elite de una localidad ya era de por sí fundamental para obtener el mando de efectivos militares ${ }^{47}$. El ser señor era una cierta garantía para el reclutamiento en determinadas zonas de la Península, a la vez que tenía los medios suficientes para cooperar — si no dirigir - en planteamientos defensivos amplios organizados por la monarquía. De ello, por supuesto, era plenamente consciente el monarca, y actuó en consecuencia. Otra cosa sería que no se dieran las circunstancias favorables a una participación más activa de los señores en la política militar de la monarquía. A la vista de las últimas investigaciones se puede deducir que las razones más importantes eran: la ausencia de verdaderas amenazas exteriores, la propia personalidad de un monarca que vendía muy cara la ayuda que se le podría prestar y que al tiempo era bastante celoso de que sus vasallos estuvieran armados, la situación ya poco desahogada de unas haciendas señoriales en las que podía respercutir también las levas de los vasallos, entre otras consideraciones ${ }^{48}$.

Pero de lo que no cabe duda, como hemos avanzado, es de esta disposición del Rey Prudente de contar con sus grandes y de la posición que les otorgaban sus respectivos regímenes señoriales. La concesión de licencias para desvincular bienes amayorazgados con el objetivo de emplear el efectivo resultante en ayuda militar de la monarquía es sólo la punta del iceberg de una estrategia de poner en funcionamiento todos los recursos defensivos del estado con unos planteamientos que miraban mucho más al pasado que al futuro.

El modo más directo era el empleo del servicio de las lanzas, como se hizo en Aragón ${ }^{49}$, por ejemplo, pero había muchos otros cauces que eran intentados por el monarca. Los archivos nobiliarios están plagados de peticiones de ayuda militar, prácticamente en todos los sentidos, de Felipe II a los grandes magnates. De los llamamientos que hizo el monarca a principio de los años setenta ya dimos cuenta en estudios recientes ${ }^{50}$. Pero este tipo de iniciativas se repartieron por otros muchos estados señoriales y en diversas épocas del reinado. En los años 1588-90, por ejemplo, el monarca mantiene una importante correspondencia con el Conde de Oropesa para que tenga preparados soldados (lanzas) y donativos y se los envíe ante diferentes coyunturas, como la noticia de la armada del Turco cerca de la isla de Menor$\mathrm{ca}^{51}$, la sublevación del Prior de Crato en Portugal ${ }^{52}$ o, más tarde, el ataque de los ingleses a Cádiz en $1596^{53}$. Igualmente, hay muchas otras peticiones a distintos nobles en estos años de amenazas, como las cartas al Duque del Infantado para el apresto de lanzas «para la guerra contra los enemigos de la religión católica» ${ }^{54}$, la dirigida al Marqués de Gibraleón avisándole del peligro de la amenaza inglesa y que tuviera dispuestos 20 jinetes $^{55}$, entre los muchos ejemplos que podríamos traer a colación. Pero, como hemos dicho, la solicitud de ayuda no

47 White, L.: «Los tercios en España: el combate», Studia Historica. Historia Moderna, Vol.19, 1998 (publicado en 2000).

48 Vid. GARCía HeRnÁn, D.: La aristocracia en la encrucijada. La alta nobleza y la Monarquía de Felipe II, Córdoba, 2000.

49 GRACIA RIVAS, M: La «invasión» de Aragón en 1591: una solución militar a las alteraciones del reino, Zaragoza, 1992, págs. 61-65.

50 GARCÍA HERNÁN, D.: «Los señoríos madrileños en la política militar de Felipe II: El Condado de Manzanares», Madrid, revista de arte, geografía e Historia, №1, (1998); y «Felipe II y el levantamiento de tropas señoriales», en MARTíneZ Millán, J. (Dir.): Congreso Internacional «Felipe II (1527-1598). Europa y la Monarquía Católica», Madrid, 1998.

51 A.H.N. Nobleza-Toledo. Frías. 24/19.

52 A.H.N. Nobleza-Toledo. Frías. 24/82, 84 y 85.

53 A.H.N. Nobleza-Toledo. Frías. 24/30.

54 A.H.N. Nobleza-Toledo. Osuna. Leg. 1731-3-10.

55 A.H.N. Nobleza-Toledo. Osuna. Leg. 255-6. 
sólo se cifraba en peticiones de soldados, sino en la concesión de donativos, como el que se pide al Conde de Priego en 1590, esperando que lo ejecute como «lo que vuestros pasados hicieron» ${ }^{56}$, e incluso en la dirección de obras para la realización de la fortificaciones, como la de Cádiz en 1596, aprovechando el enorme prestigio de este mismo Conde de Priego, para que hiciera contribuir decisivamente en lo económico a la ciudad ${ }^{57}$.

Por otra parte, el recurso a las armas por parte de la nobleza, si bien no puede ni compararse con los agitados siglo bajomedievales, tampoco se puede decir que estuvo completamente ausente en el reinado del Rey Prudente. Primitivo PLA ALBEROLA ha puesto de manifiesto que en esta época se dan en el reino de Valencia una serie de luchas nobiliarias con verdaderos ejércitos que, juntos, sumaban hasta 1.000 hombres. Estas luchas, que fueron las últimas de este tipo en el reino de Valencia, se dieron entre el Conde de Concentaina y el Barón de Planes ${ }^{58}$. Eso sin contar los casos aislados de empleo sistemático y decidido de la violencia en dominios señoriales confiando en la seguridad de la posición social del aristócrata en cuestión - muchas veces envuelto en esos feos asuntos- y sus atribuciones señoriales, como se pudo ver en las refriegas sobre asuntos de caza en el condado de Chinchón, por ejemplo ${ }^{59}$.

\section{LAS ARMAS DE LOS NOBLES}

Este protagonismo militar — al menos potencial— de los nobles sólo se pudo dar a partir de su disposición en el control de determinado número de hombres y de armas. Como es obvio, la posesión o no de estas últimas era fundamental para calibrar el grado defensivo de un territorio determinado. En general, durante el reinado de Felipe II hubo un verdadero problema por las sensibles carencias en cuanto armamento de los súbditos de la monarquía. Los que estaban obligados a poseer una determinada arma, no la poseían, como se demostraba cuando habían de presentarse a los alardes, si es que se presentaban. Los intentos de resucitar la figura de los caballeros cuantiosos con Felipe II tuvieron en esta tesitura precisamente una de las principales causas de su fracaso. Esta circunstancia era contraria a los intereses de la monarquía, sobre todo en momentos circunstanciales, aunque no todo lo contraria que pudiera parecer a simple vista, ya que, en el fondo, esta situación se debía en buena medida al resquemor que tenía el monarca de que sus vasallos pudieran estar armados en un eventual enfrentamiento contra su poder (el recuerdo de las Comunidades, como se encarga de subrayar Cabrera de Córdoba en varios pasajes de su famosa biografía, estaba bien presente en la mente del monarca $\left.{ }^{60}\right)$. La prohibición de fabricar e introducir arcabuces en Castilla por los problemas de orden público que habían traído ${ }^{61}$, así como la prohibición de mantener este tipo de armas en las proximidades de la caza real, habían tenido además un importante efecto en este sentido ${ }^{62}$. De hecho, los intelectuales y arbitristas clamaron contra esta situación tan

56 De esta forma, los antepasados sirven para justificar los privilegios, pero también, como se ve, para justificar las exigencias del monarca. A.H.N. Nobleza-Toledo. Priego. Caja 3, D. 10.

57 A.H.N. Nobleza-Toledo. Priego. Caja, 3, D.11.

$58 \mathrm{Al}$ Conde de Concentaina se le llegó a condenar a destierro, pero la Corona no llega a intervenir su estado señorial. Desde el destierro, en la raya portuguesa, gobierna su estado señorial mediante un procurador general. PLA ALBEROLA, P.: «El ocaso de las bandería nobiliarias en Valencia. D. Ximen Pérez Ruiz de Corella», en V.V.A.A.: Ejército, Ciencia y Sociedad en la España del Antiguo Régimen, Alicante, 1995.

59 A.H.N. Nobleza-Toledo. Frías. Caja 1443. Leg. 18, №1 (s. fol.).

60 CABrera de Cordoba, L.: Historia de .... Op. Cit.

61 GARCía HeRnÁN, D.: «Felipe II y el levantamiento de tropas señoriales», en MARTíNEZ MiLláN, J. (Dir.): Congreso Internacional «Felipe II (1527-1598). Europa y la Monarquía Católica», Madrid, 1998.

62 Garcia Hernan, D.: «Los señoríos madrileños en la política militar de Felipe II: El Condado de Manzanares», Madrid, revista de arte, geografía e Historia, $\mathrm{N}^{\circ} 1$, (1998). 
sin sentido, toda vez que en el ejército era costumbre hecha norma que los soldados se costearan sus propias armas ${ }^{63}$. Frías Cascales, por ejemplo, a principios del siglo XVII se dirigía al rey para asegurarle que no se debía desconfiar de los vasallos, como se había hecho hasta entonces (en clara alusión al reinado de Felipe II) porque tengan armas, ya que los reyes cristianos y sabios habían de confiar en ellos y no temer que se rebelaran porque, según él, los reyes de España habían ganado «los corazones y voluntades de sus súbditos» ${ }^{64}$. La situación que describe explica tales recomendaciones:

\begin{abstract}
«Bien sé que en algunas partes de España ay gente alistada, batallón, cuantiosos, guardas y jinetes, pero muchos de los que están obligados a tener armas y caballos no los tienen, como lo he visto y experimentado en Córdoba y otras partes del Andaluzía, cumpliendo los días de las muestras y reseñas con lo que les prestan los vezinos, demás de lo que a los unos y a los otros les falta lo mejor, que es armas y ejercicio militar, porque sin éste es todo lo demás potencia fantástica y pintada, y cuerpo sin alma; y así conviene mucho que en toda España aya armas demás de las dichas, y milicia práctica, y días y lugares determinados para ella; de tal forma y modo que cada y cuando se ofrezca ocasión, a causa de enemigos domésticos o extraños se halle fácilmente en cada parte y rincón tan gran copia de soldados diestros y bien armados que les puedan ser freno duro, causándoles terror y asombro y desconfianza de poder conseguir ni lograr sus dañados intentos, viendo a toda España cerrada y guardada debajo de la llave de pedernal» 65 .
\end{abstract}

La situación por tanto dejaba mucho que desear con respecto a los vasallos. Pero ¿y en lo que se refiere a los otros vasallos del rey, a los que eran vasallos del monarca pero al mismo tiempo señores? ¿Se encontraban tan desarmados como ellos?. La respuesta a esta pregunta pensamos que es crucial, por cuanto permite calibrar uno de los aspectos más importantes que definen el potencial militar de este poderoso grupo social. Los recuentos que hemos realizado de armas de algunos casos pensamos que muy significativos nos arrojan resultados verdaderamente sorprendentes. Pensamos que quien controlaba las armas en una España con dificultades todavía para la plena y rápida aplicación del poder real en todos sus rincones, como era la de Felipe II, representaba un poder fáctico e intimidatorio — cuando no realque brinda la posibilidad de explicar muchas situaciones de respeto y perpetuación del poder señorial que se da en esta época ${ }^{66}$.

Todo ello en un contexto en el que el desarrollo de las armas y las fortificaciones estuvo condicionado tanto por la moda como por la necesidad. En toda Europa los príncipes coleccionaron armas de fuego y casas de campo con elementos prestados del nuevo tipo de fortificaciones para propósitos puramente decorativos. En tal atmósfera, los fundidores de armas tuvieron gran cuidadado en que sus armas tuvieran un aspecto tan hermoso como letal ${ }^{67}$.

Ante tales aficiones decorativas y funcionales no es casualidad que de los recuentos de armas que hemos realizado, todos ellos nos demuestran un desequilibrio más que evidente entre las armas de fuego de los señores y de sus vasallos, incluso las de todos ellos juntos. Veamos en primer lugar el importante caso del Duque del Infantado.

63 QuATRefages, R.: Los tercios, Madrid, 1983, pág. 181.

64 B.N.M. Mss. 8.446. Fols. 84 y ss.

65 Para solucionar todos estos males de abandono de armas, fortalezas y hombres, Frías Cascales propone un remedio un tanto audaz: puesto que había una pragmática que prohibía llevar trajes de seda a los que desempeñaban oficios mecánicos y esta pramática no se cumplía, proponía que el rey la retirara a condición de que aquellas personas pudieran llevar sedas con tal que cada uno tuviera en su casa a su costa y no a la del rey las armas y las municiones que les fuera mandado: arcabuces con sus requisitos, picas con morriones, alabardas, espadas y rodelas, y también coseletes las personas de más calidad. Además, estos hombres debían practicar periódicamente y bajo la supervisión de oficiales. B.N.M. Mss. 8.446. Fols. 84 y ss.

66 Un análisis interpretativo y de carácter general sobre los principales presupuestos del régimen señorial en esta época y sus relaciones de poder con la monarquía en GARCIA HERNAN, D.: La aristocracia en la encrucijada. La alta nobleza y la Monarquía de Felipe II, Córdoba, 2000.

67 HALE, J.: «War and public opinion in the fifteenth and sixteenth centuries», Past and Present, 22, (1962). 
Poco después de la muerte de Felipe II se hizo un inventario de las armas que guardaba en su espléndido palacio de Guadalajara. En esa fecha se le hizo cargo al nuevo armero mayor, Baltasar de Córdoba, de las armas contenidas en la armería ducal, quedando reflejada su contabilidad en una serie de pliegos que, en distintas fechas, aunque con cantidades en todas ellas muy parecidas, han llegado hasta nosotros. En total, en toda esta documentación con diversos recuentos desde 1538, ocupa más de 300 páginas, con datos bastante reveladores. En primer lugar, hay que tener presente que, a pesar de la diferencia de fechas, la armería no se puede considerar como un centro estático o de museo, sino como algo vivo, como se desprende de las instrucciones que le llegaron al armero mayor. Se pone de manifiesto en estos pliegos que el duque se preocupaba por la compra de armas, incluso algunas traídas de Milán, por su reparación, por su reparto para los alguaciles y alcaides de su estado señorial, etc ${ }^{68}$.

Pero si esta actividad relacionada con las armas era importante, no lo era menos el número total de objetos de guerra de los que estamos hablando, que es muy significativo por sí solo. En la relación de 1619 (como hemos dicho, no varía mucho en cuanto a sus cantidades con respecto a lass realizadas con anterioridad), que es la más detallada que conservamos, siendo armero mayor Don Alonso de Montoya, se consignaba, entre otras armas, un cargo de 138 arneses, 29 ballestas, 109 lanzas jinetas y 38 picas. Pero lo más significativo son los números de las armas de fuego, de las que poseía el duque un auténtico arsenal en un palacio cortesano como era el suyo de Guadalajara. En el pliego de los mosquetes, con sus respectivos frascos y frasquillos que les permitían ofrecer su temible potencia de fuego se consignan 105, algunos con forma de culebrina, de diversos tipos. Además de 36 escopetas y 19 pistoletes, en el pliego correspondente a los arcabuces se consignan nada menos que un total de 489 arcabuces con sus respectivos aderezos ${ }^{69}$; es decir una cantidad que se conservaba — con sus respectivos cuidados - en tiempo de paz y significaba lo suficiente como para armar una fuerza de campaña verdaderamente importante para imponer por la fuerza, si fuera necesario, muchos planteamientos. Todo esto es especialmente relevante sobre todo si tenemos en cuenta, que en los recuentos mandados realizar por Felipe II en 1569-70 de los hombres en edad de combatir y de las armas que había en todo el Condado de Manzanares (que, englobando a varias villas y pueblos, pertenecía, con vasallos que se contaban por miles al mismo duque), sólo apareció un arcabuz en la villa de Manzanares y dos escopetas y dos arcabuces en la de Colmenar Viejo ${ }^{70}$. La comparación es verdaderamente estremecedora, y denota un desequilibrio que por fuerza se tenía que ver reflejado en las relaciones de poder, en una época en que los resortes coercitivos del Estado eran todavía bastante difusos. A todo ello había que añadir la artillería que poseía el duque. En el mismo palacio sólo conservaba cinco tiros de bronce con sus cureñas que estén reflejados en los pliegos de la armería y localizados en la llamada sala grande del Palacio. Pero en la fortaleza de Manzanares, sabemos que, al menos en el periodo de 1531 a 1565 había en el entresuelo, en una sala «grande y principal» muchas armas de picas y ballestas, así como tiros de lombardas y culebrinas. Además, había en otras partes de la fortaleza otros cañones y tiros potentes y gruesos en número de cinco o seis que, según dice algún testigo de la época, «cavía por la boca una persona mediana» ${ }^{71}$. Si bien es cierto que, con el tiempo, al final se acabarían perdiendo ${ }^{72}$.

Ahora bien, cabe preguntarnos: ¿Es excepcional el caso del Duque del Infantado? La respuesta tiene que ser claramente negativa. Ya Thompson hacía referencia de que el Duque

68 B.N.M. Mss. 8.726. Fols. 239 y ss.

69 B.N.M. Mss. 8.726.. Fols. 138-252.

70 GARCía HeRnÁN, D.: «Los señoríos madrileños en la política militar de Felipe II: El Condado de Manzanares», Madrid, revista de arte, geografía e Historia, $\mathrm{N}^{\mathrm{o}} 1$, (1998).

71 A.H.N. Nobleza-Toledo. Osuna. Leg. 2.396 -25.

72 Parece ser que por el tremendo coste que suponía conservar habitable y con los correspondientes sueldos de oficiales señoriales este castillo. A.H.N. Nobleza-Toledo. Osuna. Leg. 2.396 -25. 
de Medina Sidonia tenía en 1579 nada menos que 26 piezas de artillería en su castillo de Santiago, que más tarde serían incrementadas hasta alcanzar en 1639 el número de $42^{73}$. Por su parte, la artillería del Conde de Chinchón en la segunda mitad del siglo XVI en la fortaleza de la villa del mismo nombre, una de las últimas de carácter militar en de aquella centu$\mathrm{ria}^{74}$, no tenía mucho que envidiar a la del señor andaluz, con un total de 4 cañones de batir, 28 piezas de campaña y 10 piezas de calibre pequeño ${ }^{75}$.

Por otro lado, en el inventario de los bienes de Enrique Enríquez de Guzmán, Conde de Alba de Liste, realizado a su muerte, nos constan entre las armas que dejó 40 coseletes con sus morriones, 50 picas, una docena de escopetas, y un cañon de campo pequeño ${ }^{76}$; mientras que en el inventario de las armas del Duque de Alburquerque realizado en 1560, en lo que se refiere a las armas de fuego, están consignadas las siguientes (todas estas armas se conservaban en el «suntuoso palacio y castillo de Cuéllar»):

\section{«-Arcabuces}

- «Un arcabuz con tres cañones y un frasco de bufano (sic.) y un molde de pelotas con su atacador. -3 ducados.

- Once arcabuces de pedernal con sus frascos y frasquillos y aparejos, a 4 ducados cada uno.

- Cuatro arcabuces de pedernal, de los de Zaragoza, con sus frascos y frasquillos y aparejos, a 5 ducados cada uno.

- Otro arcabuz de Zaragoza, de mecha, con su frasco y frasquillo y aparejos. -4 ducados.

- Diez arcabuces de los de la provincia, sin llaves, con sus frascos y frasquillos. -2 ducados.

- Un arcabuz de los de la cámara, con sus cargas y adereços. -10 ducados»77.

En realidad, los números hablan por sí solos. Muchos de los grandes señores en la segunda mitad del siglo XVI se podía decir que tenían en sus armas un potencial realmente importante y nada desdeñable ni por la monarquía ni por sus propios vasallos. Los monarcas, por fuerza, debían contar con este potencial, como lo hizo Felipe II; aunque sus esfuerzos en este sentido no cumplieran las expectativas.

Por muy autoritario que haya podido parecer su reinado a la Historiografía tradicional, en detrimento de las autoridades intermedias, sus hechos de gobierno estaban claramente condicionados por su propia visión y la de sus contemporáneos sobre las funciones militares tradicionales de la nobleza. Los códigos del valor, del honor, e incluso de la sangre de los antepasados, todavía estaban muy presentes en la milicia, y los caballeros tenían muchas ventajas

73 Este autor pone también otros ejemplos, según la documentación de la Sección de Guerra Antigua de Simancas, en las personas del Marqués de Cerralbo (en 1579) y el Marqués de las Navas (en 1589). THOMPSON, I.A.A.: Guerra y decadencia: gobierno y administración en la España de los Austrias, 1560-1620, Barcelona, 1981, págs. 181-184. Con respecto a este último personaje, pero en 1572, hemos podido constatar la posesión por parte de este aristócrata de un total — por contar sólo las armas de fuego — de 340 arcabuces, 18 pistoletes, 36 escopetas viejas, dos medias culebrinas, dos medios cañones, cuatro cuartos de cañón, 18 sacres, 15 falconetes y 30 mosquetes. A.G.S. C.C. Diversos. Leg. 25, 2.

74 COOPER, E.: Castillos señoriales de Castilla S.XV y XVI., Madrid, 1991, Vol.1. pág. 698.

75 A.H.N. Nobleza-Toledo. Frías.

76 A.G.P. S. Histórica. Caja 322. N9. Hay inventarios de armas de otros personajes importantes, como Francisco de Eraso en esta misma caja aunque en otros expedientes.

77 Entre las otras armas se consignaban las siguientes: -Armas de la gineta. -Arneses. -Armas de Real. -Rodelas. -Cubiertas y sobrecubiertas. - Hierros de picas y de lanzas de armas. -Picas, alabardas y martillos. -Lanzas de armas y escudos de Real. -Hierros de lanza gineta y lanzones. -Espadas, estoques y alfanges. -Espadas roperas. «Inventario del moviliario, alhajas, ropas, armería y otros efectos del Excmo. Sr. D.Beltrán de la Cueva, tercer Duque de Alburquerque», publicado en la revista de Archivos, Bibliotecas y museos, $2^{a}$ época, T ${ }^{o}$ I., Madrid, Imprenta de D.G. Hernando, 1883. (págs. 109-110). 
en este sentido. Todo esto añadido al propio valor que tenía el señorío en sus cometidos defensivos, con sus respectivos recursos y la jurisdicción que lo amparaba, era una realidad social que no se podía perder ni mucho menos de vista. El control de las armas, permitido también por esta jurisdicción, era tan importante como el valor estratégico de los territorios señoriales; y los grandes aristócratas lo sabían. Por ello no dejaron de disponer, según los casos analizados, de grandes depósitos de armamento durante buena parte de la Edad Moderna. De esta forma, no sólo era su enorme superioridad económica y social y sus cargos políticos, sino también la fuerza, al menos intimidatoria, de sus armas lo que permitía perpetuar situaciones sociales. Tanto para las presiones que podían venir de arriba - el rey-, como las posibles originarias desde abajo — sus vasallos - los grandes tenían como reserva el argumento incontestable de la fuerza militar, independientemente de que estuviera llamado o no a imponerse. Su enorme imagen de superioridad también estaba amparada así en la potencia disuasoria de las armas. Los cambios en el Antiguo Régimen son escasos también por motivos como éstos.

DAVID GARCÍA HERNÁN

Universidad Carlos III de Madrid 